\title{
Vulvar bowen disease treated successfully by Photodyamic therapy: about two cases
}

\section{Hanane Bay Bay, Selma Benkirane, Loubna Benchat, Sara Elloudi, Mariame Meziane, Fatima Zahra Mernissi}

\author{
Department of Dermatology, University Hospital Center Hassan II, Faculty of Medicine, Fez, Morocco
}

Corresponding author: Prof. Hanane Bay Bay, E-mail: hananebaybay@gmail.com

\begin{abstract}
The Bowen's disease (BD) is a carcinoma in situ, its vulvar location is a therapeutic challenge. The ideal treatment should be not only effective, well tolerated, but also with optimal aesthetic result, in this context, photodynamic therapy (PDT) is an attractive therapeutic strategy thanks to unique properties of tumor selectivity. Imiquimod can be a potential treatment modality for lesions that are difficult to treat with surgical excision. We report two cases of patients effectively treated with PDT and Imiquimod 5\% as additional therapy for vulvar MB.
\end{abstract}

Key words: Bowen's disease; Vulva; Photodynamic therapy; Imiquimod; Carcinoma in situ

\section{INTRODUCTION}

Bowen Disease (BD) is a carcinoma in situ; its vulvar location is a therapeutic challenge $[1,2]$. Dynamic phototherapy (PDT) is an interesting therapeutic strategy thanks in particular to the original properties of tumor selectivity $[3,4]$. Also, Imiquimod can be a potential treatment modality for lesions that are difficult to treat with surgical excision $[5,6]$.

We report the cases of two patients effectively treated with PDT and Imiquimod 5\% as a therapeutic adjunct for vulvar MB.

\section{CASE REPORT}

\section{Case 1}

47 year old woman, with no notable pathological history, who had vulvar pruritus that had been evolving for 1 year. The dermatological examination showed a plate at the level of the large lip, $6 \mathrm{~cm}$, erythematous well limited, regular edges surmounted by a whitish coating, non-peelable, taking almost the entire plate (Fig. 1).

\section{Case 2}

57 years old woman, diabetic and hypertensive, who had a pruritus vulva evolving since 1 year. The dermatological examination had objectified a whitish coating, not decolable, sitting at the level of the small lip (Fig. 2).

The dermoscopy showed in both patients a homogeneous glomerular vascularization in favor of a bowen disease, confirmed by the histological examination. The histopathological findings revealed papillomatosis, koilocytosis and clumping cells with atypical nuclei (Fig. 3).

The patients had benefited from a conservative treatment with 2 sessions of PDT with as photosensitizing agent the methyl aminolevulinate at a rate of $100 \mathrm{~J} / \mathrm{cm} 2$ at one week intervals. The suites were simple. An addition by Imiquimod 5\% for 3 months was introduced. A histological control, performed in the 2 patients, after 3 months of treatment, had not objectified tumor cells. The follow up is 2 years for the first case and 1 year and half for the second (Figs. 4-6).

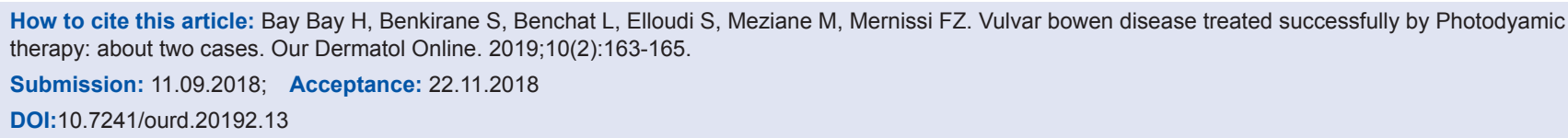


www.odermatol.com

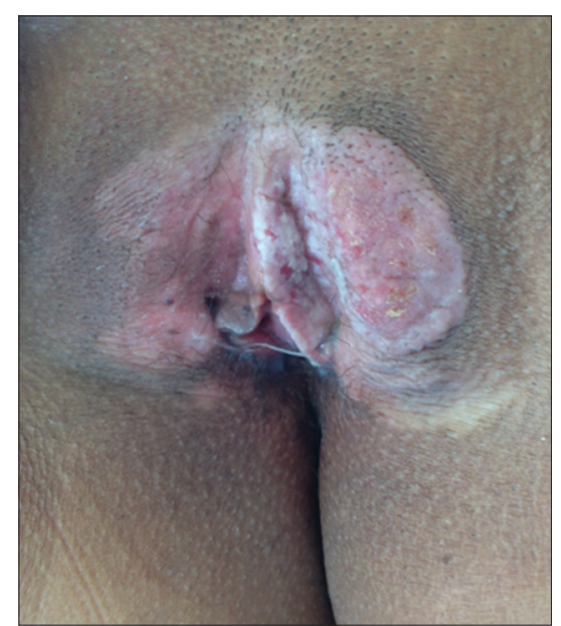

Figure 1: Erythroleukoplastic large plaque of the vulva.

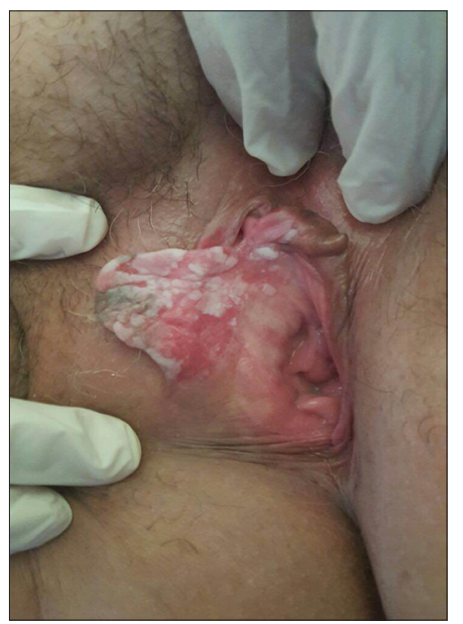

Figure 2: Erythroleukoplastic of the small lip and vulva.

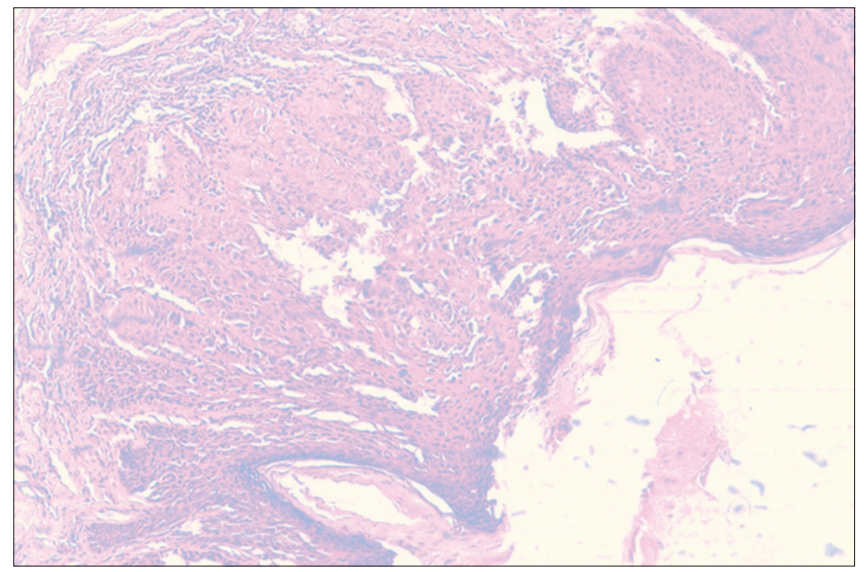

Figure 3: Histology: Papillomatosis, koilocytosis and clumping cells with atypical nuclei. H\&E x10.

Prior to the study, patient gave written consent to the examination and biopsy after having been informed about the procedure.

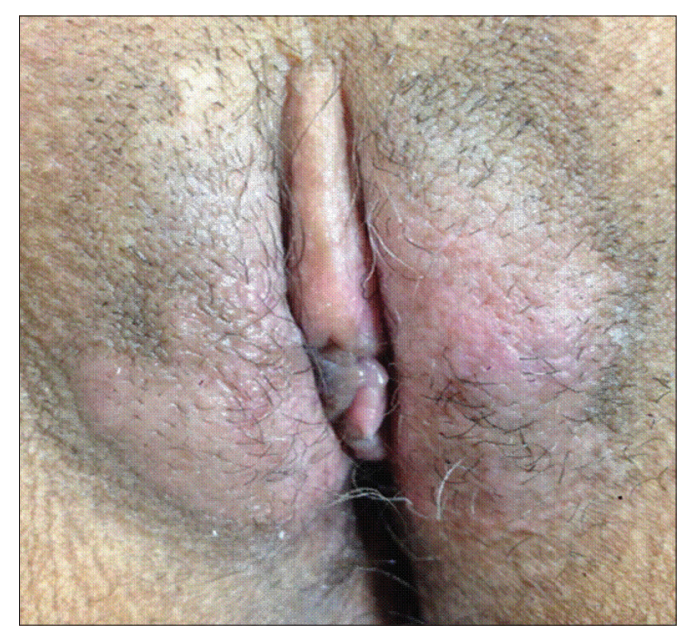

Figure 4: Clinical control after PDT with good improvement.

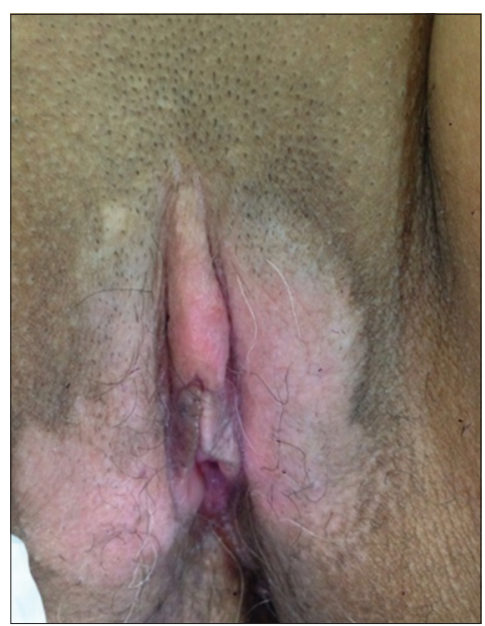

Figure 5: Clinical control after supplement treatment with imiquimod.

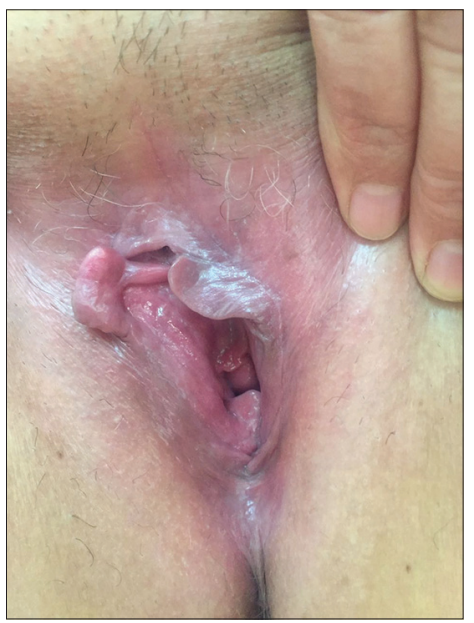

Figure 6: Clinical control after PDT and Imiquimod with good improvement.

\section{DISCUSSION}

BD or vulvar carcinoma in situ usually manifests as a single, proliferating, leucoplastic or erythroplasic 
plaque that extends centrifugally very progressively without central healing $[1,2]$.

There are several therapeutic modalities, surgical, local, and non-surgical ablative [3-6].

The therapeutic decision takes into account the size and number of lesions, and the age of the patient, but also the experience of the practitioner and the choice of the patient as well as his immune status. Although it has the advantage of histological control, surgery at the vulvar level can be debilitating and mutilating with severe consequences [4-6]. Dynamic phototherapy (PDT) is increasingly used to treat superficial cancers of the skin. It acts through a photosensitizer that triggers a phototoxic reaction that produces singlet oxygen and other free radicals with cytotoxic and vasculotoxic effects leading to necrosis and cell apoptosis [7-9].

Several cases of bowen disease favorably treated with PDT have been reported but few of them related to the genital location [10].

PDT allowed a non-invasive treatment, a satisfactory aesthetic and functional result even if it's extensive form [7]. We specify that treatment with Imiquimod alone requires a more aggressive treatment, of prolonged duration and offers only partial results in the literature. However, in some report cases, Imiquimod allowed an interesting result in pagetoid form and small area $[5,6]$. For our extensive cases, we opted for a PDT with a supplement therapy by Imiquimod due to its immunomodulatory action to potentiate the effect of PDT and minimize the risk of recurrence. Finally, further studies are needed to develop its use in the treatment of Bowen's Disease in the area vulvar with and without therapeutic adjuncts.

\section{CONCLUSION}

PDT is an effective and non-invasive therapeutic method for large bowen vulvar disease, providing a good aesthetic and functional outcome. Combinad therapy with Imiquimod as immunomodulatory, potentiate the effect of PDT and minimize the risk of recurrence.

\section{Consent}

The examination of the patient was conducted according to the Declaration of Helsinki principles.

\section{REFERENCES}

1. Strayer DS, Santa Cruz DJ. Carcinoma in situ of the skin: a review of histopathology. J Cutan Pathol. 1980;7:244-59.

2. Krüger-Corcoran D, Vandersee S, Stockfleth E. Precancerous tumors and carcinomas in situ of the skin. Internist (Berl). 2013;54:671-82.

3. HK Kang, J-H Yun, Y-M Son, JY Roh, Jk Lee, Photodynamic Therapy for Bowen's Disease of the Vulva Area. Ann Dermatol. 2014; 26: 241-5.

4. Bath-Hextall FJ, Matin RN, Wilkinson D, Leonardi-Bee J. Interventions for cutaneous Bowen's disease. Cochrane Database Syst Rev. 2013;6:CD007281.

5. Yadav P, Mendiratta V, Rana S, Makhija M. Pagetoid Bowen's disease of vulva: Excellent response to imiquimod. Indian J Dermatol Venereol Leprol. 2016; 82: 734-7.

6. Kishi C, Shimizu A, Kato M, Amano H, Ishikawa O. Successful treatment of genital Bowen's disease with imiquimod 5\% cream. Int J STD AIDS. 2015;26:752-4.

7. López N, Meyer-Gonzalez T, Herrera-Acosta E, Bosch R,Castillo R, Herrera E. Photodynamic therapy in the treatment of extensive Bowen's disease. J Dermatolog Treat. 2012;23:428-430.

8. Basset-Seguin N. Revue Panoramique de la PDT Principe, photosensibilisateurs, sources de lumières et indications validées en dermatologie, Ann Dermatol Vénéréol. 2013;140(Supp 2):223-8.

9. Alisson RR, Morissy K. Photodynamic therapy (PDT), PDT mechanisms. Clin Endosc. 2013;46:24-5.

10. Kim YJ, Kang HY, Lee ES, Kim YC. Photodynamic therapy for treatment of Bowen's disease. Korean J Dermatol. 2007;45:237-41.

Copyright by Hanane Bay Bay, et al. This is an open-access article distributed under the terms of the Creative Commons Attribution License, which permits unrestricted use, distribution, and reproduction in any medium, provided the original author and source are credited.

Source of Support: Nil, Conflict of Interest: None declared. 